\title{
Closing the yellow gap with Eu- and Tb-doped GaN: one luminescent host resulting in three colours
}

\author{
Cordula Braun, ${ }^{\left[\mathrm{a}{ }^{*}\right.}$ Liuda Mereacre, ${ }^{\text {[a] }}$ \\ Zheng Chen, ${ }^{[\mathrm{b}]}$ and Adam Slabon ${ }^{[\mathrm{c}]}$
}

[a] * Dr. C. Braun, L. Mereacre, Karlsruhe Institute of Technology (KIT)

Institute for Applied Materials (IAM)

Herrmann-von-Helmholtz-Platz 1,

D-76344 Eggenstein-Leopoldshafen

E-mail: Cordula.Braun@kit.edu

[b] Z. Chen,

Institute of Inorganic Chemistry, RWTH Aachen University,

Landoltweg 1,

D-52056 Aachen

[c] Prof. Dr. A. Slabon,

Department of Materials and Environmental Chemistry,

Stockholm University,

Svante Arrhenius väg 16 C,

10691 Stockholm, Sweden 


\section{Abstract:}

Gallium nitride ( $\mathrm{GaN})$ is a key material when it comes to light-emitting diodes (LEDs) and has pushed the LED revolution in lighting and displays.

The investigations of Nakamura and coworkers, being awarded the Nobel prize in 2014, made p-doping of GaN easily accessible by a post-growth thermal annealing treatment and triggered the invention of highly efficient blue-emitting diodes.

The concept of down-conversion of a GaN-based blue LED offers also the possibility to provide efficient generation of monochromatic, high-color purity light resulting in a highly efficient warm-white all-nitride phosphor-converted light emitting diode (pc-LED).

Although the down conversion of blue light from InGaN LEDs has become a dominant technique for producing white light, there are still some technical challenges, e.g. the immiscibility of $\mathrm{GaN}$ and $\mathrm{InN}$ and the lattice mismatch between the substrate and $\mathrm{InGaN}$, that have to be overcome.

Here we demonstrate the doping of bulk GaN with europium, terbium and the combination of both resulting in intriguing luminescence properties, pushing the role of $\mathrm{GaN}: \mathrm{Eu}, \mathrm{Tb}$ as a chief component in future light emitting diodes.

This colour tuning proves that one luminescence host can provide three colours (red, green and orange) and that even the so called "yellow gap" could be closed with a III-nitride.

By using one material for all colours, it will be possible to overcome the technical challenges in building up LED devices, which will open up new capabilities for modern highly efficient phosphors. 


\section{Main}

Gallium nitride $(\mathrm{GaN})$ has set the benchmark in the last decades when it comes to light-emitting diodes (LEDs). As a key material, it has driven the LED revolution in lighting and displays. The lighting industry with its various market segments, including automotive lighting, indoor and outdoor lighting, medical applications, lifestyle products and vertical farming has arisen from these fundamental discoveries enabled by the exploration of light's interaction with matter. ${ }^{[1,2]}$ The first light emission from a solid-state material driven by an electric current was reported in 1907 by H.J. Round ${ }^{[3]}$ and this outreaching discovery paved the way of electroluminescence and highly efficient phosphors in modern LED technology. This investigation triggered further studies on the optoelectronic processes taking place in semiconductors based on the recombination of electric charges. ${ }^{[4,5]}$ The first GaAsP LEDs was reported by Craford et al. ${ }^{[6,7]}$ in 1971 and 1972, but many technical challenges still were to overcome. The development of metal-organic vapour phase epitaxy (MOVPE) technique led the foundation for all future milestones to come. The final breakthrough came from the investigations of Nakamura and coworkers ${ }^{[8-10]}$, making p-doping of $\mathrm{GaN}$ and its ternary alloys (InGaN, AlGaN) easily accessible by a post-growth thermal annealing treatment and launched the invention of highly efficient blue-emitting diodes.

In 2014, the Nobel Prize in Physics was awarded to Isamu Akasaki, Hiroshi Amano and Shuji Nakamura for "the invention of efficient blue light-emitting diodes which has enabled bright and energy-saving white light sources".[11]

White light from LEDs can be build up combining a red, green and blue emitting semiconductor or by phosphors down-converting the emission of short wavelength emitting GaN/InGaN LEDs. $^{[12-14]}$

One of the challenges here is the comparatively low external quantum efficiency (EQE)

of the green-emitting semiconductors, because of the lattice mismatch between the substrate and $\mathrm{InGaN}$, causing high defect density, immiscibility of $\mathrm{GaN}$ and $\mathrm{InN}^{[15]}$ or chemical interaction with packaging materials. As such, there is an urgent necessity of developing a solidstate material with a very narrow emission bandwidth in the green spectral region. ${ }^{[14]}$

The concept of down conversion of a GaN-based blue LED offers also the possibility to provide efficient generation of monochromatic, high-color purity light resulting in a highly efficient warm-white all-nitride phosphor-converted light emitting diode (pc-LED). Eu ${ }^{2+}$-doped nitridosilicates and oxonitridosilicates emerged as important host lattices for phosphorconverted light-emitting diodes (pc-LEDs) due to their very high chemical and thermal stability, their very high quantum efficiency of the luminescence process and their very low thermal 
quenching. ${ }^{[13,16-26]}$ Namely $\mathrm{M}_{2} \mathrm{Si}_{5} \mathrm{~N}_{8}: \mathrm{Eu}^{2+}$ and $\mathrm{MSi}_{2} \mathrm{O}_{2} \mathrm{~N}_{2}: \mathrm{Eu}^{2+}(\mathrm{M}=$ alkaline earth $)$ have been employed as highly effective red-orange (2-5-8) and yellow-green (1-2-2-2) phosphors, respectively.

Even the so called "yellow gap", neither III-nitrides nor III-phosphides had been able to close, could be bridged with $(\mathrm{Ba}, \mathrm{Sr})_{2} \mathrm{Si}_{5} \mathrm{~N}_{8}: \mathrm{Eu}^{2+} \cdot{ }^{[14]}$

Just recently, new Mg-nitridosilicates $\left(\mathrm{Ca}\left[\mathrm{Mg}_{3} \mathrm{SiN}_{4}\right]: \mathrm{Ce}^{3+}, \quad \operatorname{Sr}\left[\mathrm{Mg}_{3} \mathrm{SiN}_{4}\right]: \mathrm{Eu}^{2+}\right.$, $\left.\mathrm{Eu}\left[\mathrm{Mg}_{3} \mathrm{SiN}\right]^{[27,28]}\right), \mathrm{Mg}$-nitridoaluminates $\left(\mathrm{M}\left[\mathrm{Mg}_{2} \mathrm{Al}_{2} \mathrm{~N}_{4}\right]: \mathrm{Eu}^{2+}\right.$ with $\mathrm{M}=\mathrm{Ca}, \mathrm{Sr}, \mathrm{Ba}^{[29]}$ and $\left.\operatorname{Sr}\left[\mathrm{LiAl}_{3} \mathrm{~N}_{4}\right]: \mathrm{Eu}^{2+[30]}\right)$ and $\operatorname{Sr}_{2}\left[\mathrm{BeAl}_{3} \mathrm{~N}_{5}\right]: \mathrm{Eu}^{2+[31]}$ emerged as next generation red phosphor materials with superior luminescence properties. ${ }^{[2]}$ Many attempts concerning MOVPE-grown $\mathrm{GaN}, \mathrm{GaN}$ nanowires/ nanocrystals, $\mathrm{GaN}$ quantum dots doped with $\mathrm{Eu}$ or in some cases with $\mathrm{Tb}$, can be found in literature. ${ }^{[32-39]}$ (see supplement) All these investigations consist only of monolayers or 2D materials having very few nanometers of thickness.

To cover the colour range from blue, over green and orange to red (ca. 450 to $650 \mathrm{~nm}$ ), a combination of InGaN und $\mathrm{AlGa}(\mathrm{In}) \mathrm{P}$ is necessary. Several challenges have to be addressed here. The decrease of the external quantum efficiency versus emission wavelength around 560 $\mathrm{nm}$, is termed the "yellow gap". ${ }^{[14]}$ The immiscibility of GaN and $\mathrm{InN}$ leads to a reduction in performance of InGaN-based LEDs with higher InN mole fractions. ${ }^{[14]}$ The lattice mismatch between $\mathrm{GaN}$, InN, GaAlN, AlGaP, different thermal expansion coefficients and the variations of the In/Al content decrease the luminescence performance tremendously.

Down conversion of blue light from InGaN LEDs by suitable color converters, especially phosphors, has become a dominant technique for producing white light, but still some technical challenges have to be overcome. One point here are structural misfits of thin films because of the different host materials. Using one bulk material $(\mathrm{GaN})$ for all colours (blue, red, green, orange) could enable therefore the next step of modern high performance GaN LEDs.

Here, we demonstrate the doping of bulk GaN with europium and terbium and the combination of both results in intriguing luminescence properties of all three doped compounds. This renders $\mathrm{GaN}: \mathrm{Eu}, \mathrm{Tb}^{[40]}$ as a prospective chief component in future light emitting diodes (LEDs).

By using various synthetic approaches (e.g. low temperature urea-based method) we succeeded to co-dope $\mathrm{GaN}$ (Chempur 99,999\%) with $\mathrm{MCl}_{3} \times 6 \mathrm{H}_{2} \mathrm{O}$ or $\mathrm{M}\left(\mathrm{NO}_{3}\right)_{3} \times 5 \mathrm{H}_{2} \mathrm{O}(\mathrm{M}=\mathrm{Eu}, \mathrm{Tb})$ as substitutes (see Figure 1). For a comparison of the powder diffraction pattern of $\mathrm{GaN}_{\mathrm{Eu}} \mathrm{Eu}^{3+}$ and GaN: $\mathrm{Tb}^{3+}$ see supplement Figure S1. SEM EDX measurements of GaN confirmed the atomic ratio of Ga:N of 1:2 and an europium and terbium content of 3-5\% was found, but no oxygen within the detection limit. 


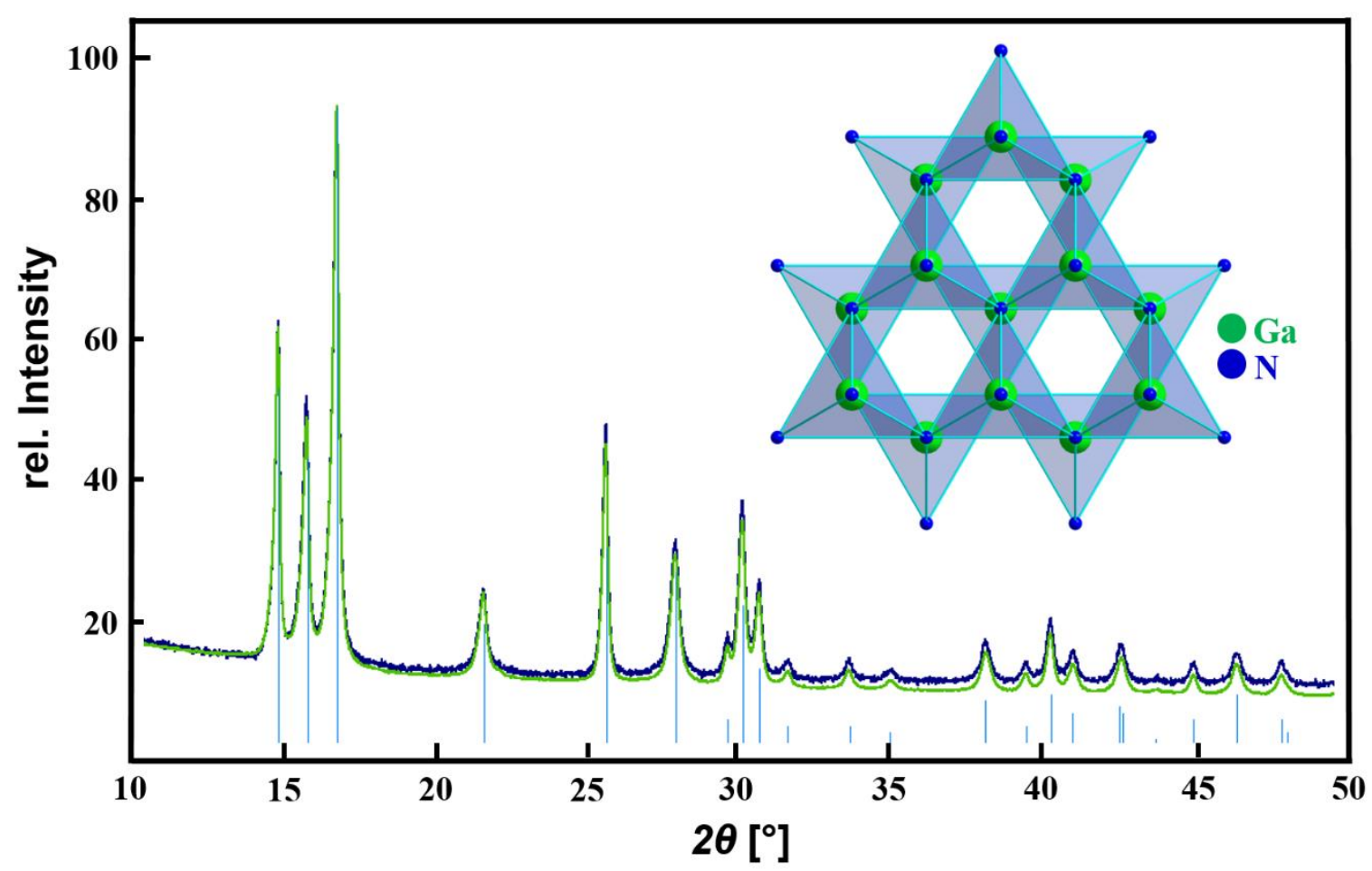

Figure 1: X-ray powder diffraction patterns of undoped GaN (blue), GaN:Tb (green) and GaN ICSD [50-07920] (bright blue), $(\lambda=0.709026 \AA)$, the inset shows the characteristic motif of the underlying $\mathrm{GaN}$ structure.

\section{Luminescence properties}

$\mathrm{Eu}^{3+}$ is considered as one of the most important activator ions with red emission corresponding to the transition ${ }^{5} \mathrm{D}_{0}-{ }^{7} \mathrm{~F}_{\mathrm{J}}(J=1-6)$. The green emission of $\mathrm{Tb}^{3+}$ is due to the transition between the emitting states of ${ }^{5} \mathrm{D}_{\mathrm{J}}$ and the excited states of ${ }^{7} \mathrm{~F}_{\mathrm{J}}$. The main intense green emission is attributed to the transition of ${ }^{5} \mathrm{D}_{4}-{ }^{7} \mathrm{~F}_{5}$, which is located at approx. $544 \mathrm{~nm}$. A relevant point here is that normally the doping ion is inserted during the main synthesis and not afterwards. In general, doping is performed with $\mathrm{Eu}^{2+}$ and only one activator ion is used. Consequently, one host can only provide one colour. Since different aspects come into play when we think about mixing colours within one host, such an approach for colour tuning offers tremendous opportunities for highly efficient phosphors.

In this work, we doped $\mathrm{GaN}$ with $\mathrm{Eu}^{3+}$ and $\mathrm{Tb}^{3+}$ as activator ions, with each individually and with both simultaneously. Figure 2c shows the CIE 1931 diagram and the colours of doped $\mathrm{GaN}$, proving that a colour tuning of one host with different activator ions and their combination is possible. Having a closer look at the CIE and the basics of colour mixing, it is clear that the combination of green and red leads to orange. (see Figure $2 \mathrm{~d}$ ) This effect could be proven in the meantime for other doped nitrides and carbodiimides as well. ${ }^{[40,41]}$ 

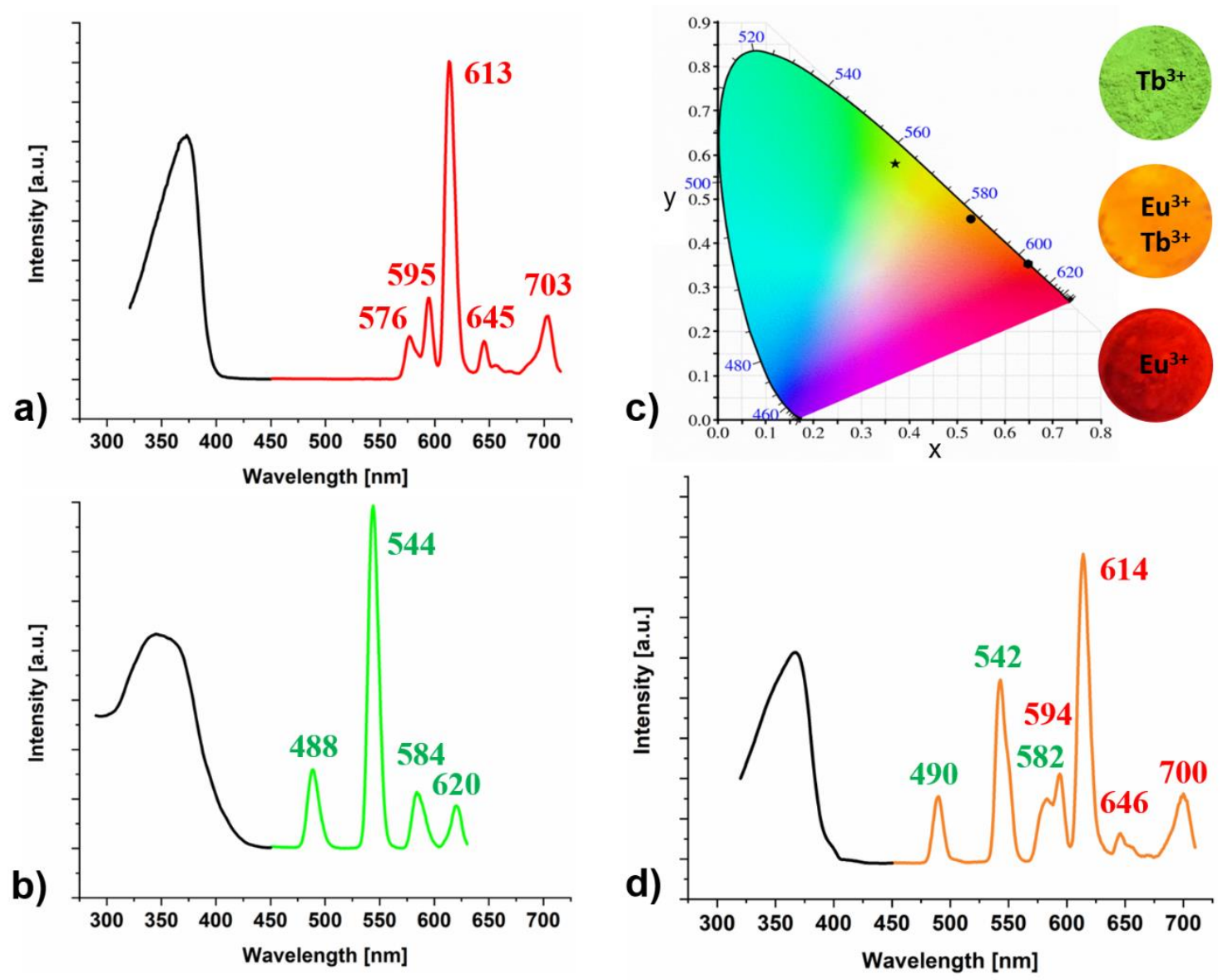

Figure 2: Excitation (black) and emission spectra (coloured) of GaN doped with a) $\mathrm{Eu}^{3+}$ (red, •), b) $\mathrm{Tb}^{3+}$ (green, $\star$ ) and d) $\mathrm{Eu}^{3+}$ and $\mathrm{Tb}^{3+}$ (orange, •), c) CIE 1931 diagram of GaN doped with $\mathrm{Tb}^{3+}, \mathrm{Eu}^{3+}, \mathrm{Tb}^{3+}$ and $\mathrm{Eu}^{3+}$.

$\mathrm{GaN}: \mathrm{Eu}^{3+}$ shows strong characteristic emission peaks of $\mathrm{Eu}^{3+}$ within the region of 570-700 $\mathrm{nm}$, indicating an energy transfer between the $\mathrm{GaN}$ host and the $\mathrm{Eu}^{3+}$ ions. The peaks associated with the intra-4f shell transitions $\left({ }^{5} \mathrm{D}_{0}-{ }^{7} \mathrm{~F}_{\mathrm{J}}\right)$ of the $\mathrm{Eu}^{3+}$ ions, are the peaks at 576, 595, 613 and $645 \mathrm{~nm}$, wherein the one at $613 \mathrm{~nm}$ is the strongest (see Figure $2 \mathrm{a}$ ). Peng et al. ${ }^{[39]}$ assumed according to extended $\mathrm{x}$-ray absorption fine structure measurements, that the $\mathrm{Eu}^{3+}$ ion substitutes the Ga site, which is in accordance with our assumption.

The excitation (monitored at $544 \mathrm{~nm}$ ) and emission spectra of $\mathrm{Tb}^{3+}$ doped $\mathrm{GaN}$ are represented in Figure 2b. The excitation spectrum exhibits a broad and intense band in the range from $290 \mathrm{~nm}$ to $380 \mathrm{~nm}$ with a peak at around $322 \mathrm{~nm}$. This broad band is attributed to $4 \mathrm{f}^{8}$ $4 f^{7} 5 d^{1}$ transition of the $\mathrm{Tb}^{3+}$ ions. The strongest emission peak is at $544 \mathrm{~nm}$ with a Full Width at Half Maximum (FWHM) $\sim 12 \mathrm{~nm}$ corresponding to the ${ }^{5} \mathrm{D}_{4} \rightarrow{ }^{7} \mathrm{~F}_{5}$ transition, while the peaks at $488 \mathrm{~nm}, 584 \mathrm{~nm}$ and $620 \mathrm{~nm}$, respectively, originate from the ${ }^{5} \mathrm{D}_{4} \rightarrow{ }^{7} \mathrm{~F}_{6},{ }^{5} \mathrm{D}_{4} \rightarrow{ }^{7} \mathrm{~F}_{4}$ and 
${ }^{5} \mathrm{D}_{4} \rightarrow{ }^{7} \mathrm{~F}_{3}$ transitions of the $\mathrm{Tb}^{3+}$ ions. Until now, green emitting phospors could only be realized as oxynitrides (e.g. $\beta-\mathrm{SiAlON}: \mathrm{Eu}^{2+[42]}$ ) or oxonitridosilicates (e.g. $\mathrm{SrSi}_{2} \mathrm{O}_{2} \mathrm{~N}_{2}: \mathrm{Eu}^{2+[43,44]}$ ). The here presented luminescence behavior of $\mathrm{GaN}: \mathrm{Tb}^{3+}$ shows that green emitting phosphors ${ }^{[40]} \mathrm{can}$ be also achieved with purely nitridic compounds.

The energy level distributions of $\mathrm{Tb}^{3+}$ and $\mathrm{Eu}^{3+}$ have a large overlap and their energy transfer has been proven to be very effective. ${ }^{[45]}$ The blue-green light of the $\mathrm{Tb}^{3+}$ transition $\left({ }^{5} \mathrm{D}_{4} \rightarrow{ }^{7} \mathrm{~F}_{6,5}\right)$ is emitted by polychromatic relaxation and the energy is transferred to the ${ }^{5} \mathrm{D}_{1}$ and ${ }^{5} \mathrm{D}_{0}$ levels of the $\mathrm{Eu}^{3+}$ by cross relaxation. The $\mathrm{Eu}^{3+}$ ions absorb the energy from $\mathrm{Tb}^{3+}$ and emit therefore orange light.

Figure $2 \mathrm{~d}$ proves that it is possible to insert two different activator ions in one host showing the typical bands of $\mathrm{Eu}^{3+}$ as well as the ones of $\mathrm{Tb}^{3+}$ in one spectrum resulting in a saturated orange body colour. However a close look reveals that this is not only a superposition of the $\mathrm{Eu}^{3+}$-and the $\mathrm{Tb}^{3+}$-spectrum of $\mathrm{GaN}$, because this orange spectrum differs clearly concerning peak form, intensity and wavelength. Here it becomes evident, that this orange colour is only possible by mixing the ions on an atomic scale and cannot be realized by a mixture of particles of the red and the green doped GaN.

To prove this GaN:Eu and GaN:Tb (same molar ratio Eu:Tb as in $\mathrm{GaN}: \mathrm{Eu}, \mathrm{Tb}$ ) have been mixed in a mortar. It becomes obvious that this does not result in an orange luminescent $\mathrm{GaN}$. Instead the red GaN:Eu is dominant in the mixture, resulting in the same red colour coordinates of just GaN:Eu. See Figure S10.

The FWHM point out the same values as in the single dopings. The line widths of the emission spectra (FWHM) of nitride-based LEDs vary typically between 20-35 nm and of phosphide-based ones between $15-25 \mathrm{~nm}^{[12]}$, however here we range from 8-12 $\mathrm{nm}$ for $\mathrm{GaN}: \mathrm{Eu}^{3+}, \mathrm{Tb}^{3+}$ which is extremely narrow banded.

The CIE values of amber emitting Phosphor $\mathrm{GaN}: \mathrm{Eu}^{3+} / \mathrm{Tb}^{3+} \mathrm{x}, \mathrm{y}=0.528,0.454$ (see Figure $2 \mathrm{c})$ are very similar to those of $(\mathrm{Ba}, \mathrm{Sr})_{2} \mathrm{Si}_{5} \mathrm{~N}_{8}: \mathrm{Eu}^{2+[14]}(\mathrm{x}, \mathrm{y}=0.579,0.416)$ and are lying therefore well within the "amber box" of the SAE specifications. ${ }^{[14]}$ This 2-5-8 nitridosilicate phosphor has been considered as an important breakthrough for bridging the "yellow gap"[14], and is established nowadays in numerous optoelectronic applications.

To elucidate if the $\mathrm{Eu}, \mathrm{Tb}$ ions really have been inserted into the $\mathrm{GaN}$ structure and the luminescence does not result from the respective doping compounds a comparison of the luminescence spectra of $\mathrm{GaN}: \mathrm{Eu}^{3+}$ and $\mathrm{EuCl}_{3} \times 6 \mathrm{H}_{2} \mathrm{O}$ is shown in Figure $\mathrm{S} 1$. As optical and luminescence spectra are highly sensitive to structural deformation of the nearest environment 
of rare-earth (RE) ions, it is clearly evident that the spectrum has changed due to the insertion of the Eu cation into the structure of GaN. Furthermore, very detailed comparisons of several $\mathrm{Eu}$ - and $\mathrm{Tb}$-doped $\mathrm{GaN}$ thin films and possible side products have been carried out (see supplement Figures S2-9). Here it becomes obvious that some luminescence spectra seem very similar, but when taking a closer look, they clearly differ. According to De Boer et al. ${ }^{[33]}$, sample growth and doping conditions play as well an important role in influencing the PL (photoluminescence) spectra.

\section{Mott-Schottky (MS) measurements}

Electrochemical Impedance Spectroscopy (EIS) is an appropriate tool to study ion diffusion and to resolve the chemical identity of the charge carriers by the use of blocking electrodes. Mott-Schottky (MS) measurements are a very sensitive technique to probe changes in the electronic band structure, i.e. charge carrier density, type of semiconducting behaviour and band edge positions, upon doping. For the elucidation of doping effect on the electronic properties of GaN, Mott-Schottky (MS) measurements were conducted for the bare and RE-doped samples. They were performed in a $0.1 \mathrm{M}$ potassium phosphate electrolyte at an applied frequency of $10 \mathrm{~Hz}$. As shown in Figure 3, all of the acquired curves show a positive slope corresponding to the characteristic of n-type semiconductors. ${ }^{[46]}$ In addition, a smaller slope for all curves can be attributed to increased charge carrier density for GaN upon doping with the rare earth metals. ${ }^{[47,48]}$ The extrapolation of the curves allows to estimate the flat band potential as the corresponding conduction band edge of n-type semiconductor. The obtained conduction band edges reveal that RE-doped GaN yield a significant negative shift, indicating RE doping can be applied to modify the (photo)electrochemical properties of GaN. ${ }^{[48-50]}$ 


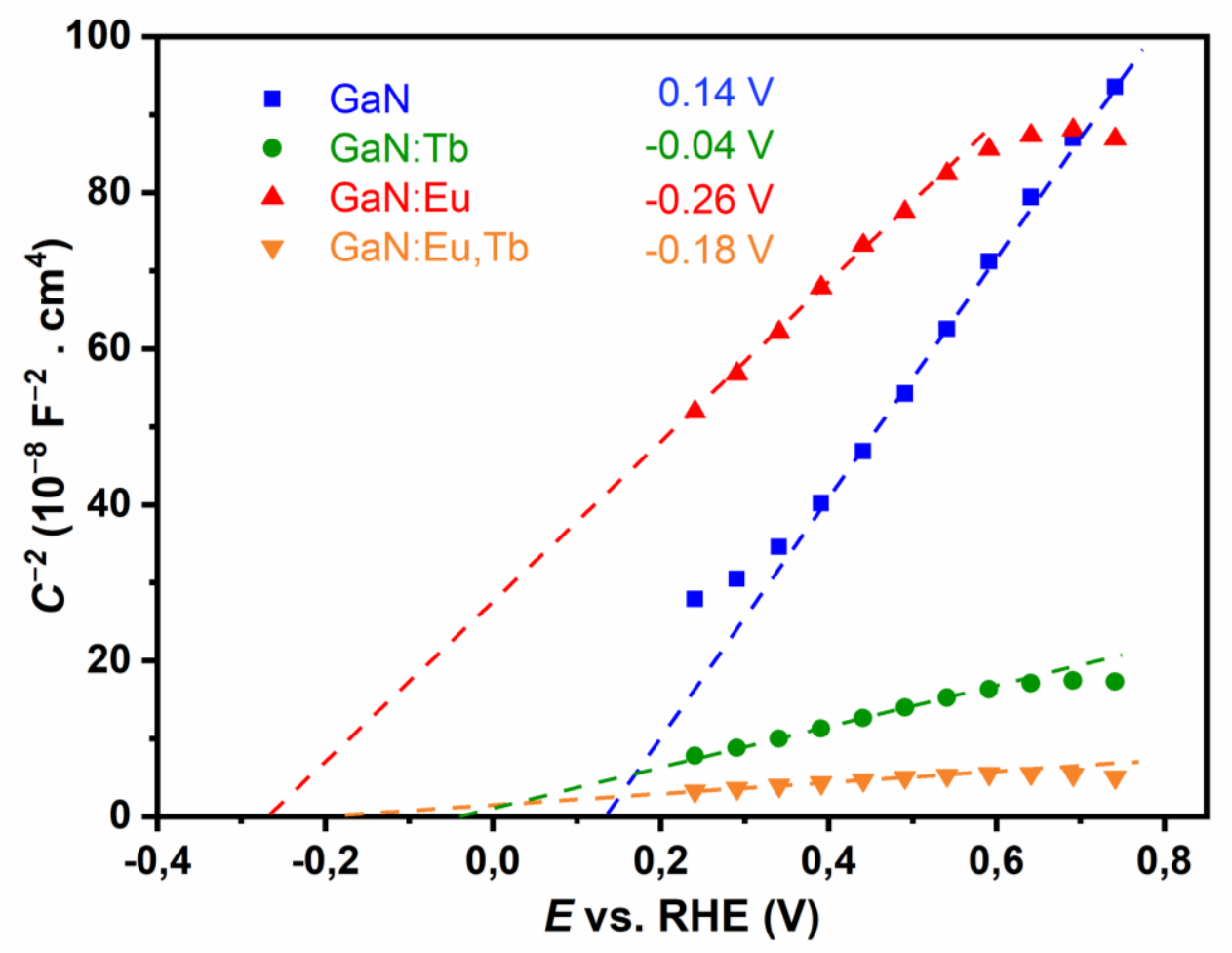

Figure 3: Mott-Schottky (MS) analysis of Electrochemical Impedance Spectroscopy (EIS) measurements of a) undoped $\mathrm{GaN}$ (blue), $\mathrm{GaN}_{\mathrm{Tb}} \mathrm{Tb}^{3+}$ (green), $\mathrm{GaN}: \mathrm{Eu}^{3+}$ (red) and $\mathrm{GaN}: \mathrm{Eu}^{3+}, \mathrm{Tb}^{3+}$ (orange); (Measurements were performed in a $0.1 \mathrm{M}$ potassium phosphate electrolyte at an applied frequency of $10 \mathrm{~Hz}$ ). The extrapolated curves at $\mathrm{y}=0$ correspond to the conduction band edges, because the materials exhibit a positive slope that is characteristic for an n-type semiconductor. The determined flatband potentials are provided in the inset.

\section{Conclusions and Outlook}

We demonstrated the doping of bulk GaN with europium and terbium and the combination of both resulting in intriguing luminescence properties of all three doped compounds (red, green, orange), rendering $\mathrm{GaN}: \mathrm{Eu}, \mathrm{Tb}$ as an prospective component in future light emitting diodes (LEDs). Our results highlight the opportunities for controlling functionality and luminescence properties of modern energy-efficient white light-emitting diodes and energy-efficient power electronic devices. Especially the closing of the "yellow gap" is a big step foreward.

The here presented methodology of doping bulk GaN applied may be generalized to create different dimensions of device architectures for LEDs, as the possibility to modify their charge transport properties by introducing dopant atoms has turned out for some time to be crucial for the performance of inorganic LEDs. 


\section{Experimental Section}

\section{Doping of GaN:}

The doping of $\mathrm{GaN}$ (Chempur 99,999\%) was realised by a successive combustion synthesis. Briefly, the respective metal chlorides $\left(\mathrm{MCl}_{3} \cdot 6 \mathrm{H}_{2} \mathrm{O}\right.$ or $\mathrm{M}\left(\mathrm{NO}_{3}\right)_{3} \cdot 5 \mathrm{H}_{2} \mathrm{O}(\mathrm{M}=\mathrm{Eu}, \mathrm{Tb}), \mathrm{NH}_{4} \mathrm{NO}_{3}$, Urea and $\mathrm{H}_{2} \mathrm{O}$ were added to the sample. This mixture was put into an oven at $400-600^{\circ}$ for 10 min. The doping, which is about 3-5\%, has been checked via EDX measurements.

\section{$X$-ray diffraction}

Powder Diffraction: X-ray diffraction experiments on powder samples of GaN were performed on a STOE STADI P powder diffractometer in Debye-Scherrer geometry with Ge(111)-monochromatized Mo-K $\alpha_{1}$ radiation $(\lambda=0.709026 \AA)$. The sample was enclosed in a glass capillary of $0.3 \mathrm{~mm}$ diameter.

\section{EDX measurements}

SEM was performed on a Zeiss Merlin microscope and for EDX we used a Quantax 400 system from Bruker.

\section{Mott-Schottky (MS) measurements}

\section{Electrodes fabrication}

$\mathrm{GaN}$ and the corresponding rare earth metal $\left(\mathrm{RE}, \mathrm{RE}=\mathrm{Eu}^{3+}, \mathrm{Tb}^{3+}\right.$ and $\left.\mathrm{Eu}^{3+} / \mathrm{Tb}^{3+}\right)$ doped semiconductor electrodes were prepared by electrophoretic deposition. Fluorine doped tin oxide (FTO) glass (2.2 mm thick, Sigma-Aldrich) was used as the substrate after sequentially ultrasonic cleaning with dilute nitric acid, acetone and ethanol for $15 \mathrm{~min}$. The dispersion was prepared by mixing $5 \mathrm{mg}$ iodine and $20 \mathrm{mg}$ sample with $20 \mathrm{ml}$ acetone, followed by treatment with ultrasounds. The electrodes were obtained after depositing the dispersed powder at $30 \mathrm{~V}$ and drying under ambient atmosphere. 


\section{Mott-Schottky (MS) measurements}

The MS measurements were performed in an electrochemical cell using a potentiostat (Gamry instruments) operating in a three-electrode setup. The deposited samples on FTO, a $1 \mathrm{M}$ $\mathrm{Ag} / \mathrm{AgCl}$ electrode and a platinum wire were used as a working electrode, a reference electrode and a counter electrode, respectively. All MS data were recorded vs. $E_{1 \mathrm{M} \mathrm{Ag} / \mathrm{AgCl}}(\mathrm{V})$, which was subsequently converted with respect to $E_{\mathrm{RHE}}(\mathrm{V})$ according to the formula: $E_{\mathrm{RHE}}(\mathrm{V})=0.235+$ $E_{1 \mathrm{M} \mathrm{Ag} / \mathrm{AgCl}}+[0.059 \times \mathrm{pH}](\mathrm{V})$ at $25^{\circ} \mathrm{C}$.

\section{Luminescence}

The luminescence spectra and quantum yield measurements were performed on a Fluorolog®3 Horiba Jobin Yvon equipped with a TBX detector picosecond photon detection device and a $450 \mathrm{~W}$ xenon lamp.

\section{Acknowledgement}

The authors gratefully acknowledge Udo Geckle (IAM-ESS KIT Karlsruhe) for the EDX and Sabine Schlabach (INT KIT Karlsruhe) for luminescence measurements. 


\section{References}

[1] P. Ball, Nat. Mater. 2015, 14, 453-453.

[2] P. Pust, P. J. Schmidt, W. Schnick, Nat. Mater. 2015, 14, 454-458.

[3] H. J. Round, Electr. World 1907, 19, 309-310.

[4] G. A. Wolff, R. A. Hebert, J. D. Broder, Phys. Rev. 1955, 100, 1144-1145.

[5] R. Braunstein, Phys. Rev. 1955, 99, 1892-1893.

[6] M. G. Craford, R. W. Shaw, A. H. Herzog, W. O. Groves, J. Appl. Phys. 1972, 43, 40754083.

[7] W. O. Groves, A. H. Herzog, M. G. Craford, Appl. Phys. Lett. 1971, 19, 184-186.

[8] S. Nakamura, T. Mukai, M. Senoh, N. Iwasa, Jpn. J. Appl. Phys. 1992, 31, L139-L142.

[9] S. Nakamura, T. Mukai, Jpn. J. Appl. Phys. 1992, 31, L1457-L1459.

[10] S. Nakamura, T. Mukai, M. Senoh, Appl. Phys. Lett. 1994, 64, 1687-1689.

[11] "The Nobel Prize in Physics 2014 - NobelPrize.org," can be found under https://www.nobelprize.org/prizes/physics/2014/summary/, n.d.

[12] R. Mueller-Mach, G. O. Mueller, in (Eds.: H.W. Yao, I.T. Ferguson, E.F. Schubert), International Society For Optics And Photonics, 2000, pp. 30-41.

[13] R. Mueller-Mach, G. Mueller, M. R. Krames, H. a Höppe, F. Stadler, W. Schnick, T. Juestel, P. Schmidt, Phys. Status Solidi A 2005, 202, 1727-1732.

[14] R. Mueller-Mach, G. O. Mueller, M. R. Krames, O. B. Shchekin, P. J. Schmidt, H. Bechtel, C.-H. Chen, O. Steigelmann, Phys. status solidi - Rapid Res. Lett. 2009, 3, 215217.

[15] N. A. El-Masry, E. L. Piner, S. X. Liu, S. M. Bedair, Appl. Phys. Lett. 1998, 72, 40-42.

[16] W. Schnick, Angew. Chemie Int. Ed. English 1993, 32, 806-818.

[17] K. Uheda, S. Shimooka, M. Mikami, H. Imura, N. Kijima, Sci. Technol. 2008, 899-902.

[18] M. Zeuner, S. Pagano, W. Schnick, Angew. Chemie - Int. Ed. 2011, 50, 7754-7775.

[19] Y. Q. Li, G. de With, H. T. Hintzen, J. Mater. Chem. 2005, 15, 4492-4496.

[20] X. Piao, T. Horikawa, H. Hanzawa, K. Machida, Appl. Phys. Lett. 2006, 88, 161908.

[21] R. J. Xie, N. Hirosaki, Sci. Technol. Adv. Mater. 2007, 8, 588-600.

[22] R.-J. Xie, N. Hirosaki, Y. Li, T. Takeda, Materials (Basel). 2010, 3, 3777-3793.

[23] T. Jüstel, H. Nikol, C. Ronda, Angew. Chemie 1998, 110, 3250-3271.

[24] C. Ronda, Ed., Luminescence, Wiley-VCH Verlag GmbH \& Co. KGaA, Weinheim, Germany, 2007.

[25] W. Schnick, Phys. Status Solidi - Rapid Res. Lett. 2009, 3, 1-2.

[26] P. Schmidt, a Tuecks, J. Meyer, H. Bechtel, D. Wiechert, R. Mueller-Mach, G. Mueller, W. Schnick, Seventh Int. Conf. Solid State Light. 2007, 6669, P6690-P6690.

[27] S. Schmiechen, H. Schneider, P. Wagatha, C. Hecht, P. J. Schmidt, W. Schnick, Chem. 
Mater. 2014, 26, 2712-2719.

[28] S. Schmiechen, P. Pust, P. J. Schmidt, W. Schnick, Nachrichten aus der Chemie 2014, $62,847-851$.

[29] P. Pust, F. Hintze, C. Hecht, V. Weiler, A. Locher, D. Zitnanska, S. Harm, D. Wiechert, P. J. Schmidt, W. Schnick, Chem. Mater. 2014, 26, 6113-6119.

[30] P. Pust, V. Weiler, C. Hecht, A. Tücks, A. S. Wochnik, A.-K. Henß, D. Wiechert, C. Scheu, P. J. Schmidt, W. Schnick, Nat. Mater. 2014, 13, 891-896.

[31] E. Elzer, P. Strobel, V. Weiler, P. J. Schmidt, W. Schnick, Chem. Mater. 2020, 32, 66116617.

[32] X. Hu, N. Zhou, Y. Hu, Y. Li, N. Chen, B. Zhao, Y. Zhang, N. Zhuang, J. Mater. Chem. C 2017, 5, 7904-7910.

[33] W. D. A. M. de Boer, C. McGonigle, T. Gregorkiewicz, Y. Fujiwara, S. Tanabe, P. Stallinga, Sci. Rep. 2015, 4, 5235.

[34] L. Bodiou, A. Braud, J.-L. Doualan, R. Moncorgé, J. H. Park, C. Munasinghe, A. J. Steckl, K. Lorenz, E. Alves, B. Daudin, J. Appl. Phys. 2009, 105, 043104.

[35] H. J. Lozykowski, W. M. Jadwisienczak, J. Han, I. G. Brown, Appl. Phys. Lett. 2000, 77, 767-769.

[36] A. Nishikawa, T. Kawasaki, N. Furukawa, Y. Terai, Y. Fujiwara, Appl. Phys. Express 2009, 2, 071004.

[37] Y. Nakanishi, A. Wakahara, H. Okada, A. Yoshida, T. Ohshima, H. Itoh, Phys. status solidi 2003, 240, 372-375.

[38] K. Hara, N. Ohtake, K. Ishii, Phys. status solidi 1999, 216, 625-628.

[39] H. Y. Peng, C. W. Lee, H. O. Everitt, D. S. Lee, A. J. Steckl, J. M. Zavada, Appl. Phys. Lett. 2005, 86, 051110.

[40] C. Braun, Bulk Materials of Doped Multinary Nitrides and Nitridosilicates, Their Production Method and Uses, 2020, EP20186968.

[41] C. Braun, L. Mereacre, W. Hua, T. Stürzer, I. Ponomarev, P. Kroll, A. Slabon, Z. Chen, Y. Damour, X. Rocquefelte, J. Halet, S. Indris, ChemElectroChem 2020, 7, 4550-4561.

[42] D. H. Kim, J. H. Ryu, S. Y. Cho, Appl. Phys. A Mater. Sci. Process. 2011, 102, 79-83.

[43] Y. Q. Li, A. C. A. Delsing, G. De With, H. T. Hintzen, Chem. Mater. 2005, 17, 32423248.

[44] V. Bachmann, T. Jüstel, A. Meijerink, C. Ronda, P. J. Schmidt, J. Lumin. 2006, 121, 441-449.

[45] D. Halmurat, T. Yusufu, Q. Wang, J. He, A. Sidike, Sci. Rep. 2019, 9, 14637.

[46] A. Lasia, in Electrochem. Impedance Spectrosc. Its Appl., Springer New York, New York, NY, 2014, pp. 251-255.

[47] R. O’Hayre, M. Nanu, J. Schoonman, A. Goossens, J. Phys. Chem. C 2007, 111, 4809- 
4814.

[48] K. Gelderman, L. Lee, S. W. Donne, J. Chem. Educ. 2007, 84, 685-688.

[49] B. Iandolo, H. Zhang, B. Wickman, I. Zorić, G. Conibeer, A. Hellman, RSC Adv. 2015, 5, 61021-61030.

[50] D. W. Hwang, J. Kim, T. J. Park, J. S. Lee, Catal. Letters 2002, 80, 53-57. 